\title{
Nephron-sparing surgery for the management of upper tract urothelial carcinoma: an outline of surgical technique and review of outcomes
}

\author{
Ruchira Nandurkar ${ }^{1 \#}$, Marnique Basto ${ }^{2 \#}$, Shomik Sengupta ${ }^{1,2,3}$ \\ ${ }^{1}$ Eastern Health Clinical School, Monash University, Clayton, Victoria, Australia; ${ }^{2}$ Department of Urology, Eastern Health, Melbourne, Victoria, \\ Australia; ${ }^{3}$ Department of Surgery, University of Melbourne, Melbourne, Victoria, Australia \\ Contributions: (I) Conception and design: S Sengupta; (II) Administrative support: S Sengupta; (III) Provision of study material or patients: None; \\ (IV) Collection and assembly of data: M Basto, R Nandurkar; (V) Data analysis and interpretation: R Nandurkar, M Basto; (VI) Manuscript writing: \\ All authors; (VII) Final approval of manuscript: All authors. \\ "These authors contributed equally to the work. \\ Correspondence to: Professor Shomik Sengupta. Eastern Health Clinical School, Level 2, 5 Arnold Street, Box Hill, Victoria 3128, Australia. \\ Email: shomik.sengupta@monash.edu.
}

\begin{abstract}
Upper tract urothelial carcinoma (UTUC) often occurs in elderly patients with multiple co-morbidities including renal impairment. As such, nephron sparing surgery (NSS) often needs to be considered. This article reviews the available NSS techniques for UTUC, including ureteroscopy, percutaneous approaches and segmental ureterectomy. PubMed and OvidMEDLINE reviews of available case series from the last 10 years demonstrated that recurrence was highly variable between studies and occurred in 19-90.5\% of ureteroscopic cases, 29-98\% of percutaneous resections and in $10.2-31.4 \%$ of patients who underwent segmental ureterectomy. The small number of included studies and variable follow up periods made comparison between techniques difficult. NSS is a necessary alternative for patients with significant comorbidities or renal impairment who cannot undergo radical nephro-ureterectomy. However, there is significant variation in oncological outcomes, with an increased risk of progression or death from cancer-salvage by radical surgery may sometimes be required.
\end{abstract}

Keywords: Upper tract urothelial carcinoma (UTUC); nephron sparing surgery (NSS); ureteroscopy; percutaneous nephroscopic surgery; segmental ureterectomy

Submitted Oct 02, 2019. Accepted for publication Nov 21, 2019.

doi: $10.21037 /$ tau.2019.11.27

View this article at: http://dx.doi.org/10.21037/tau.2019.11.27

\section{Introduction}

Upper tract urothelial carcinoma (UTUC) is a relatively rare malignancy, and accounts for around $5-10 \%$ of all urothelial carcinomas (UC). Radical nephroureterectomy (RNU) is the gold standard for the surgical management of UTUC, however nephron sparing surgery (NSS) is utilised in patients with a solitary kidney, significant renal impairment, multiple bilateral UTUC or comorbidities that will incur unacceptable risk with RNU (1). Additionally,
NSS for low risk UTUC may be performed as a primary treatment option with no difference in oncological outcome compared with RNU (2).

The surgical techniques for NSS include endoscopic management (ureteroscopy and percutaneous access) and segmental ureterectomy. Endoscopic techniques allow for histopathological diagnosis and management of the tumour primarily by laser ablation. While ureteroscopy is more commonly used for the management of UTUC, percutaneous access may be useful for tumours that are 
difficult to reach, while accepting a slightly higher rate of complications. Instillation of topical agents such as Bacillus Calmette-Guerin (BCG) and mitomycin C (MMC) are also possible in combination with ureteroscopy or percutaneous access.

The technique for segmental ureterectomy will depend on tumour location and extent. UTUC occurs more commonly in the renal pelvis than the ureter (3:1 ratio) (3). Of the ureteric tumours, $70 \%$ occur in the distal ureter, $25 \%$ in the mid ureter and $5 \%$ in the proximal ureter. As a result, techniques for resection of distal ureteric tumours are more commonly utilised including distal ureterectomy with reimplantation, or uretero-ureterostomy of iliac and lumbar segments of ureter.

The literature in the domain of NSS is sparse and raises questions about our current guidelines and management strategies. In this article we outline the surgical techniques for NSS for UTUC and review the literature from 2009 to 2019 using the MeSH terms 'upper tract urothelial carcinoma', 'UTUC', 'treatment', and 'nephron-sparing'. Outcome measures are variable between studies but include tumour recurrence, progression to RNU, cancer-specific survival (CSS) and overall survival (OS).

\section{Endoscopic management-ureteroscopy and percutaneous access}

Endoscopic management of urothelial tumours are most commonly performed via a retrograde approach, however percutaneous access can be considered for low risk UTUC in the renal pelvis. The goals of management are to diagnose the lesion, obtain samples for cytology or histology, and complete tumour ablation. Preoperative planning should include urine studies (culture and cytology), blood tests (full blood count, electrolytes and renal function), and radiographic upper tract imaging.

\section{Ureteroscopy}

Preoperatively the patient should be consented and informed of the likely need for an early second look, and more stringent surveillance compared to surgical management. Depending on prior management patients may already be preoperatively stented.

General anaesthesia is preferable however spinal anaesthesia may be acceptable in high risk patients. Rigid cystoscopy is performed with a systematic assessment of the bladder for co-existing synchronous tumours. Transurethral resection of bladder tumour should always be prepared for in these patients, especially in those with prior bladder recurrence.

A good quality retrograde pyelogram is performed at the commencement of the procedure to assess the location of the tumour. A contralateral image should be obtained in the case of endoscopic surveillance. A guidewire is then passed into the renal pelvis under fluoroscopic guidance. Washings for cytological examination from the renal pelvis or ureter may be useful at this point, if a diagnosis has not yet been established.

Most ureteral tumours will require a rigid ureteroscope, short or long, however some tumours may be better suited to a flexible ureteroscope. A short ureteroscope can be used if more distal ureteral tumour is anticipated based on imaging. The tumour can be initially debulked and tissue obtained for histological analysis, using flexible cold cup biopsy forceps or wire basket to snare the tumour base. One of the pitfalls of biopsy in this setting is that the specimens obtained ureteroscopically are often sub-optimal, leading to under-staging in many cases (4).

Tumour ablation can be achieved to the tumour base after debulking, or in some instances may be appropriate for ablation of the whole tumour e.g., large or sessile tumours. This can be performed using bugbee diathermy or laser fulguration. A laser generator capable of holmium:yttrium-alluminium-garnet (Ho:YAG) and neodymium $(\mathrm{Nd})$ :yytrium-aluminium-garnet ( $\mathrm{Ng}$ :YAG) is selected for use based on appropriate tissue penetration (5). Ho:YAG is suited for tumours in the ureter due to lesser depth of penetration and hence reduced stricture formation. Nd:YAG may be preferred for bulkier renal pelvis tumours due to greater depth of penetration. Care must be taken not to resect the tumour too deeply as the ureteric wall is much thinner than the bladder. Additionally, attempts should be made not to fulgurate circumferentially to minimise the risk of stricture formation. For more extensive tumours a second look within six weeks of the initial resection is recommended to ensure complete eradication of the tumour.

On completion of the most distal tumour, the proximal ureter and renal pelvis should be inspected using a flexible 
ureteroscope. Similarly, for tumours in the renal pelvis the flexible uretero-pyeloscope can be placed over the existing guidewire or a second safety wire. Alternatively, the existing wire can be used to pass an access sheath and flexible endoscope placed within this working channel.

A ureteric stent is commonly placed at the end of the procedure and removed in two weeks for more extensive tumours. For small superficial tumours or where instrumentation of the ureter was minimal, it may be reasonable to leave the stent on a string or a temporary ureteric catheter for removal within the first week. Furthermore, a ureteric catheter may be left at the end of the case for instillation of topical agents (see below). For patients at risk of stricture development such as ablation of circumferential tumours, or those with known ureteric strictures it may be sensible to leave the stent in for longer. Consideration should be given to leaving an in-dwelling catheter for best drainage of the upper tracts in patients who will remain in hospital.

The surveillance period is not well established for tumour ablation of low risk UTUC and given the risk of under-staging and under-grading, there should be a low threshold for progressing to radical surgical intervention in case of recurrence. For those who underwent tumour ablation as definitive NSS, initial endoscopic surveillance is often undertaken at 3-months. Where no tumour is found, the interval can be lengthened to 6-monthly with upper tract imaging performed yearly.

Table 1 summarises the outcomes of ureteroscopic management of UTUC in recent studies. The number of patients within each study was small ranging from 20 to 82 . Rate of recurrence, the most commonly reported outcome measure, was highly variable and noted in between 19 and $90.5 \%$ of cases. Progression to RNU occurred at a median rate of $19 \%$ (range, $0-42.8 \%$ ) over these studies. CSS was between $84-100 \%$ but with quite variable follow up periods (26 months to 5 years). Two studies reported OS at 5 years follow up of $75 \%$ and $45 \%$ respectively. The variable length of follow up makes comparison difficult between studies.

\section{Percutaneous access}

Percutaneous access may be best for tumours that are difficult to access endoscopically including lower pole tumours or for patients with more complex anatomy. However this technique is being utilised less frequently due to improvements in flexible ureteroscopes that permit better deflection and access (16).

Access is gained in a similar manner as for percutaneous stone removal. Given the risk of tumour seeding all attempts should be made to perform this procedure in one sitting. A nephrostomy tube may be left at the conclusion of the procedure and can provide access in the event of needing a second look. A nephrostogram may be obtained prior to removal, and in some instances the nephrostomy tube may be used for instillation of topical agents (see below).

The risk of complications associated with percutaneous access are generally greater than retrograde endoscopic alternatives. This includes the risk of bleeding and perinephric haematoma which may require blood transfusion or arterial embolisation. As previously mentioned, tumour seeding can occur along the perirenal space, cutaneous tract or systemically (17).

Table 2 summarises outcomes of percutaneous management of UTUC, including 3 available studies over the most recent ten years; one of these was a mixed cohort including both ureteroscopic and percutaneous resection of tumour. Motamedinia et al. reported the risk of recurrence as $37 \%$ in low grade and $63 \%$ in high grade tumours, with a median follow up of 66 months. Of the 114 patients included in this study, $13 \%$ progressed to RNU and the OS was $40 \%$. Strijbos and van der Heij reported the outcomes of 44 patients with UTUC who experienced a $50 \%$ recurrence rate and $27.5 \%$ rate of progression to RNU.

\section{Upper urinary tract instillation of topical agents}

Topical agents can be instilled antegrade via a nephrostomy tube left in situ following percutaneous treatment or retrograde via a $5 \mathrm{~F}$ ureteric catheter left in situ after endoscopic management. Reflux via an in-dwelling double $\mathrm{J}$ pigtail stent of agents instilled intravesically has also been proposed. However, the adequacy of drug delivery to the renal pelvis is not always reliable. There are no standardised protocols on instillation techniques and the literature is scant in this domain, however BCG and MMC seem the most commonly investigated. Currently the OLYMPUS (Optimised Delivery of Mitomycin for primary UTUC study) trial is prospectively studying Mitogel for patients with low grade UTUC and is due for completion in 2020 (21). In addition to these agents, intravesical instillation of physiological saline or distilled water has been 
Table 1 Reported outcomes for ureteroscopic resection of upper tract urothelial carcinoma in the most recent 10 years

\begin{tabular}{|c|c|c|c|c|}
\hline Study & $\mathrm{N}$ & Treatment & Duration of follow-up & Outcomes \\
\hline Scotland et al. 2018 (6) & 80 & $\begin{array}{l}\text { Ureteroscopy with laser } \\
\text { ablation }\end{array}$ & $5 \mathrm{yrs}$ & $\begin{array}{l}90.5 \% \text { ipsilateral recurrence } \\
31.7 \% \text { progressed in grade } \\
\text { CSS: } 84 \% \\
\text { OS: } 75 \%\end{array}$ \\
\hline Fajkovic et al. 2013 (8) & 20 & Endoscopic treatment & $5 \mathrm{yrs}$ & $\begin{array}{l}25 \% \text { local recurrence } \\
15 \% \text { bladder recurrence } \\
0 \% \text { progression to } \mathrm{RNU} \\
\text { OS: } 45 \%\end{array}$ \\
\hline Cutress et al. 2012 (10) & 73 & Ureteroscopy & $\begin{array}{l}\text { Median } 54 \text { mths } \\
\text { Range 1-223 mths }\end{array}$ & $\begin{array}{l}68 \% \text { upper tract recurrence } \\
\text { 19\% progression to RNU } \\
\text { CSS: }(5 \mathrm{yr}) 88.9 \% \\
\text { OS: } 69.7 \%\end{array}$ \\
\hline Raymundo et al. 2011 (11) & 21 & $\begin{array}{l}\text { Percutaneous and/or } \\
\text { ureteroscopic resection }\end{array}$ & $\begin{array}{l}\text { Mean } 17.9 \text { mths } \\
\text { Range } 13.2-24.6 \text { mths }\end{array}$ & $\begin{array}{l}48 \% \text { ipsilateral recurrence } \\
5 \% \text { mortality UTUC-related } \\
42.8 \% \text { progressed to RNU }\end{array}$ \\
\hline Cornu et al. 2010 (13) & 35 & Ureteroscopy & $\begin{array}{l}\text { Median } 30 \text { mths } \\
\text { Range 12-66 mths }\end{array}$ & $\begin{array}{l}60 \% \text { recurrence } \\
11 \% \text { progression to RNU } \\
\text { CSS: } 100 \% \\
\text { OS: } 100 \%\end{array}$ \\
\hline Pak et al. 2009 (14) & 57 & Ureteroscopy & $\begin{array}{l}\text { Mean } 53 \text { mths } \\
\text { Range } 24-146 \text { mths }\end{array}$ & $\begin{array}{l}80.7 \% \text { renal preservation } \\
5.5 \text { Mean recurrences/patient } \\
\text { CSS: } 94.7 \% \\
\text { OS: } 93 \%\end{array}$ \\
\hline Hoffman et al. 2014 (15) & 25 & Ureteroscopic resection & $\begin{array}{l}\text { Median } 26 \text { mths } \\
\text { Range } 12-126 \text { mths }\end{array}$ & $44 \%$ recurrence \\
\hline
\end{tabular}

$\mathrm{N}$, no. of patients in sample population; CSS, cancer-specific survival; OS, overall survival; RNU, radical nephroureterectomy; yrs, years; mths, months. 
Table 2 Reported outcomes for percutaneous resection of upper tract urothelial carcinoma in the most recent 10 years

\begin{tabular}{|c|c|c|c|c|}
\hline Study & $\mathrm{N}$ & Treatment & Duration of follow-up & Outcomes \\
\hline \multirow{2}{*}{$\begin{array}{l}\text { Motamedinia et al. } \\
2016(18)\end{array}$} & \multirow{2}{*}{141} & \multirow{2}{*}{ Percutaneous ablation } & \multirow{2}{*}{ Median 66 mths } & $13 \%$ progression to $\mathrm{RNU}$ \\
\hline & & & & OS: $40 \%$ \\
\hline \multirow{2}{*}{$\begin{array}{l}\text { Strijbos \& van der Heij } \\
2016 \text { (19) }\end{array}$} & \multirow[t]{2}{*}{44} & \multirow[t]{2}{*}{ Percutaneous resection } & \multirow[t]{2}{*}{ Median 53 mths } & $50 \%$ recurrence rate \\
\hline & & & & Complications seen in $35 \%$ \\
\hline \multirow{2}{*}{$\begin{array}{l}\text { Adamis \& Varkarakis } \\
2011(20)\end{array}$} & \multirow{2}{*}{\multicolumn{2}{|c|}{ 18-44 URS, PNRT }} & \multirow[t]{2}{*}{132 mths } & Recurrence: URS: 29-98\%, PNRT: 23-88\% \\
\hline & & & & $\begin{array}{l}\text { CSS at } 5 \text { yrs: URS: } 86.5-100 \% \text {, } \\
\text { PNRT: } 69.2-94.1 \%\end{array}$ \\
\hline
\end{tabular}

$\mathrm{N}$, no. of patients in sample population; mths, months; LG, low grade; HG, high grade; RNU, radical nephroureterectomy; URS, ureteroscopy; PNRT, percutaneous nephroscopic resection of tumour; CSS, cancer-specific survival; OS, overall survival.

utilised at the time of RNU and shown to reduce the rate of post-operative bladder recurrence (22).

\section{Segmental ureteral resection}

Segmental ureteral resection can be performed depending on tumour location. Care should be taken to obtain adequate margins of clearance. A significant advantage is that a full thickness histological specimen is obtained for adequate staging and grading. Concurrent lymph node dissection can also be carried out. Traditionally, segmental resection has been carried out by open surgery, but minimally invasive approaches have also been described including laparoscopic and robotic surgery.

For distal ureteric tumours complete distal ureterectomy can be performed with ureteric reimplantation. The type of reconstruction will vary depending on the length of ureter taken: for shorter segments uretero-neocystostomy can be performed. For higher lesions necessitating longer lengths of ureteric resection, a psoas hitch and/or Boari flap can provide up to $10 \mathrm{~cm}$ of additional bladder mobility. Resection of iliac and lumbar portions of ureter with reconstruction by uretero-ureterostomy, are associated with higher risks in comparison to complete distal ureterectomy (2). The excised defect can be bridged with a spatulated anastomosis over a stent. Longer defects may require nephropexy, ileal replacement or auto-transplantation, however these approaches also carry greater risks and are consequently rarely undertaken. Historical procedures such as partial pyelectomy, partial nephrectomy and open resections of tumours in the renal pelvis are also very rarely performed, with RNU preferred.

The literature is again scarce in regard to segmental ureterectomy, we identified 7 reports over the last 10 years, outlined in Table 3. Tumour recurrence rates varied between $10.2 \%$ and $31.4 \%$, with a median follow up duration between 26 and 51.5 months. CSS was between $77 \%$ and $89 \%$ in most studies. However, OS was more variable between 31 and $91 \%$. Rate of death was reported in 2 studies at $5.7 \%$ over 48.3 months in one study, and $20.9 \%$ over 50 months in another.

\section{Conclusions}

A range of nephron sparing options are available for the surgical treatment of UTUC. These techniques are best suited to smaller tumours of lower grade and stage, and for each approach certain favourable anatomical and pathological features are ideal. NSS may be considered imperative in patients with solitary kidneys or pre-existing renal impairment unless the risks and morbidity of renal replacement therapy are to be taken on. The risks of recurrence are always a concern after NSS, although some published case series report favourable outcomes. Appropriate patient selection, careful surgical technique and close surveillance are crucial to the success of these approaches. 
Table 3 Reported outcomes for segmental or distal ureterectomy of upper tract urothelial carcinoma in the most recent 10 years

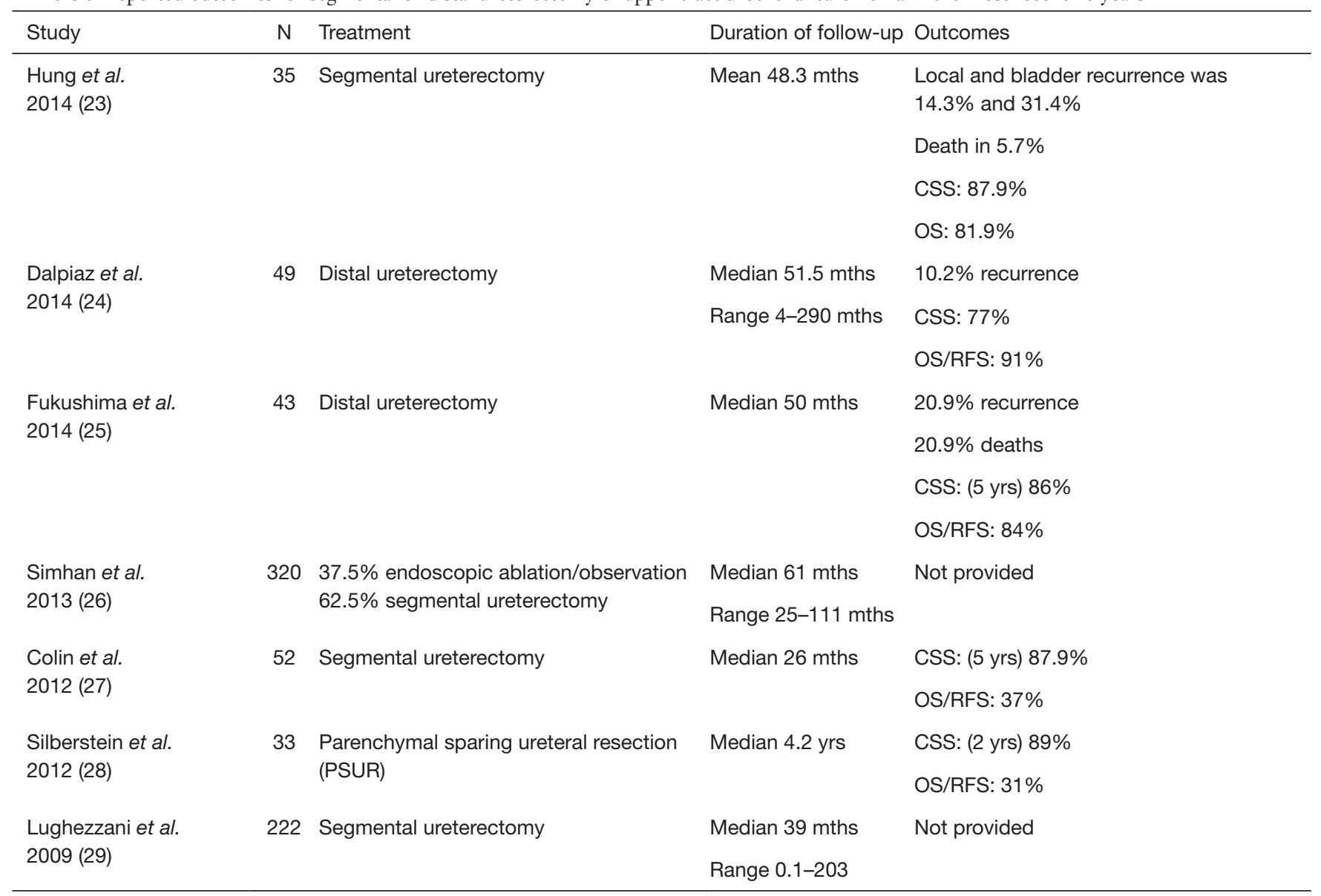

$\mathrm{N}$, no. of patients in sample population; mths, months; CSS, cancer-specific survival; OS, overall survival; RFS, recurrence free survival.

\section{Acknowledgments}

Funding: None.

\section{Footnote}

Provenance and Peer Review: This article was commissioned by the editorial office, Translational Andrology and Urology for the series "Surgery for Urologic Cancers". The article has undergone external peer review.

Conflicts of Interest: The series "Surgery for Urologic Cancers" was commissioned by the editorial office without any funding or sponsorship. SS served as the unpaid Guest Editor of the series and serves as an unpaid editorial board member of Translational Andrology and Urology from Jul 2018 to Jun 2020. The authors have no other conflicts of interest to declare.
Ethical Statement: The authors are accountable for all aspects of the work in ensuring that questions related to the accuracy or integrity of any part of the work are appropriately investigated and resolved.

Open Access Statement: This is an Open Access article distributed in accordance with the Creative Commons Attribution-NonCommercial-NoDerivs 4.0 International License (CC BY-NC-ND 4.0), which permits the noncommercial replication and distribution of the article with the strict proviso that no changes or edits are made and the original work is properly cited (including links to both the formal publication through the relevant DOI and the license). See: https://creativecommons.org/licenses/by-nc-nd/4.0/.

\section{References}

1. Fiuk JV, Schwartz BF. Upper tract urothelial carcinoma: 
Paradigm shift towards nephron sparing management. World J Nephrol 2016;5:158-65.

2. Rouprêt M, Babjuk M, Böhle A, et al. EAU Guidelines on Urothelial Carcinomas of the Upper Urinary Tract. European Association of Urology 2016. Available online: https://uroweb.org/wp-content/uploads/EAU-GuidelinesUrothelial-Carcinomas-of-the-Upper-UrinaryTract-2016-1.pdf

3. Linton KD, Catto JW. Upper tract urothelial carcinoma. J Clin Urol 2013;6:272-9.

4. Vemana G, Kim EH, Bhayani SB, et al. Survival Comparison Between Endoscopic and Surgical Management for Patients With Upper Tract Urothelial Cancer: A Matched Propensity Score Analysis Using Surveillance, Epidemiology and End Results-Medicare Data. Urology 2016;95:115-20.

5. Smith J, Howards S, Preminger G, et al. Hinman's Atlas of Urologic Surgery. 4 ed. Elsevier, 2016.

6. Scotland KB, Kleinmann N, Cason D, et al. Ureteroscopic Management of Large $>=2 \mathrm{~cm}$ Upper Tract Urothelial Carcinoma: A Comprehensive 23-Year Experience. Urology 2018;121:66-73.

7. Musi G, Mistretta FA, Marenghi C, et al. Thulium Laser Treatment of Upper Urinary Tract Carcinoma: A Multi-Institutional Analysis of Surgical and Oncological Outcomes. J Endourol 2018;32:257-63.

8. Fajkovic H, Klatte T, Nagele U, et al. Results and outcomes after endoscopic treatment of upper urinary tract carcinoma: the Austrian experience. World J Urol 2013;31:37-44.

9. Grasso M, Fishman AI, Cohen J, et al. Ureteroscopic and extirpative treatment of upper urinary tract urothelial carcinoma: a 15 -year comprehensive review of 160 consecutive patients. BJU International 2012;110:1618-26.

10. Cutress ML, Stewart GD, Wells-Cole S, et al. Longterm endoscopic management of upper tract urothelial carcinoma: 20-year single-centre experience. BJU International 2012;110:1608-17.

11. Raymundo EM, Lipkin ME, Bañez LB, et al. Third Prize: The Role of Endoscopic Nephron-Sparing Surgery in the Management of Upper Tract Urothelial Carcinoma. J Endourol 2011;25:377-84.

12. Gadzinski AJ, Roberts WW, Faerber GJ, et al. Longterm outcomes of nephroureterectomy versus endoscopic management for upper tract urothelial carcinoma. J Urol 2010;183:2148-53.

13. Cornu JN, Roupret M, Carpentier X, et al. Oncologic control obtained after exclusive flexible ureteroscopic management of upper urinary tract urothelial cell carcinoma. World J Urol 2010;28:151-6.

14. Pak RW, Moskowitz EJ, Bagley DH. What Is the Cost of Maintaining a Kidney in Upper-Tract Transitional-Cell Carcinoma? An Objective Analysis of Cost and Survival. Journal of Endourology 2009;23:341-6.

15. Hoffman A, Yossepowitch O, Erlich Y, et al. Oncologic results of Nephron sparing endoscopic approach for upper tract low grade transitional cell carcinoma in comparison to nephroureterectomy - a case control study. BMC Urology 2014;14:97.

16. Cutress ML, Stewart GD, Zakikhani P, et al. Ureteroscopic and percutaneous management of upper tract urothelial carcinoma (UTUC): systematic review. BJU Int 2012;110:614-28.

17. Sengupta, Harewood. Transitional cell carcinoma growing along an indwelling nephrostomy tube track. BJU 1998;82:591.

18. Motamedinia P, Keheila M, Leavitt DA, et al. The Expanded Use of Percutaneous Resection for Upper Tract Urothelial Carcinoma: A 30-Year Comprehensive Experience. J Endourol 2016;30:262-7.

19. Strijbos WE, van der Heij B. Percutaneous resection of upper tract urothelial cell carcinoma: When, how, and is it safe? Asian Journal of Urology 2016;3:134-41.

20. Adamis S, Varkarakis J. Minimally invasive approach in the management of upper- urinary-tract tumours. Scand J Urol Nephrol 2011;45:381-7.

21. Azizi M, Cheriyan SK, Peyton CC, et al. Optimal Management of Upper Tract Urothelial Carcinoma: an Unmet Need. Curr Treat Options Oncol 2019;20:40.

22. Yamamoto S, Sakamoto S, Imamura Y, et al. Intravesical irrigation might prevent bladder recurrence in patients undergoing radical nephroureterectomy for upper urinary tract urothelial carcinoma. Int J Urol 2019;26:791-6.

23. Hung SY, Yang WC, Luo HL, et al. Segmental ureterectomy does not compromise the oncologic outcome compared with nephroureterectomy for pure ureter cancer. Int Urol Nephrol 2014;46:921-6.

24. Dalpiaz O, Ehrlich G, Quehenberger F, et al. Distal ureterectomy is a safe surgical option in patients with urothelial carcinoma of the distal ureter. Urol Oncol 2014;32:34.e1-8.

25. Fukushima H, Saito K, Ishioka J, et al. Equivalent survival and improved preservation of renal function after distal ureterectomy compared with nephroureterectomy in patients with urothelial carcinoma of the distal ureter: A propensity score-matched multicenter study. Int J Urol 
2014;21:1098-104.

26. Simhan J, Smaldone MC, Egleston BL, et al. Nephronsparing management vs radical nephroureterectomy for low- or moderate-grade, low-stage upper tract urothelial carcinoma. BJU Int 2014;114:216-20.

27. Colin P, Ouzzane A, Pignot G, et al. Comparison of oncological outcomes after segmental ureterectomy or radical nephroureterectomy in urothelial carcinomas of the upper urinary tract: results from a large French multicentre study. BJU Int 2012;110:1134-41.

Cite this article as: Nandurkar R, Basto M, Sengupta S. Nephron-sparing surgery for the management of upper tract urothelial carcinoma: an outline of surgical technique and review of outcomes. Transl Androl Urol 2020;9(6):3160-3167. doi: 10.21037/tau.2019.11.27
28. Silberstein JL, Power NE, Savage C, et al. Renal Function and Oncologic Outcomes of Parenchymal Sparing Ureteral Resection Versus Radical Nephroureterectomy for Upper Tract Urothelial Carcinoma. J Urol 2012;187:429-34.

29. Lughezzani G, Jeldres C, Isbarn H, et al.

Nephroureterectomy and segmental ureterectomy in the treatment of invasive upper tract urothelial carcinoma: A population-based study of 2299 patients. Eur J Cancer 2009;45:3291-7. 